\title{
Contribution of Aggregation to the Growth Mechanism of Seeded Calcium Carbonate Precipitation in the Presence of Polyacrylic Acid
}

\author{
Marcel Donnet, ${ }^{\dagger}$ Anne Aimable,* Jacques Lemaître, and Paul Bowen \\ Powder Technology Laboratory (LTP), Materials Institute, Swiss Federal Institute of Technology, Ecole \\ Polytechnique Fédérale de Lausanne (EPFL), 1015 Lausanne, Switzerland
}

Received: February 4, 2010; Revised Manuscript Received: August 11, 2010

\begin{abstract}
Our work investigates the precipitation mechanism of a seeded calcium carbonate reaction, by using cryogenic TEM to observe the early stages of the reaction. The early precipitation of a hydrated phase is proposed as an intermediate phase before transformation into calcite. Thermodynamic modeling in conjunction with $\mathrm{pH}$, surface potential measurements, and colloidal stability modeling demonstrate that calcite growth is dominated by agglomeration. This is in agreement with the cryogenic TEM observations, which suggest oriented attachment dominates early aggregation. The final stage of the reaction is described by a ripening mechanism that is significantly inhibited when high concentrations of polyacrylic acid (PAA) are used. The different concentrations of PAA lead to significant differences in the final particle substructure observed using cross section TEM. At low PAA concentrations, single crystal particles result, coherent with the proposed early oriented attachment mechanism and interfacial energy calculations. A core shell model is proposed for high PAA concentrations, whereas internal ripening of nanosized pores has been observed for low PAA concentrations, suggesting trapped solvent during the rapid initial particle formation at the relatively high supersaturations $(S=30)$ investigated.
\end{abstract}

\section{Introduction}

To understand and control precipitation reactions is a major challenge for industrial crystallization. The control of particle size, surface area, and density is desirable for powders such as calcium carbonate so that those powders can be tuned for different applications, such as paper processing, ${ }^{1}$ sensor applications, ${ }^{2}$ and food processing. ${ }^{3}$ The nature of the precipitate will depend on the reaction conditions; presence of additives or seeds that, in turn, may influence the growth mechanism; self-assembly; crystallographic phase; shape; size; and internal structure of the particles. ${ }^{4-8}$ Calcium carbonate, in addition to being an important material for industrial applications, is also present in many living organisms, which has also led to much work on the growth mechanisms that give the very particular morphologies observed in nature. ${ }^{9-12}$

In the current study, the precipitation of calcium carbonate from relatively concentrated solutions $(0.02 \mathrm{M})$ involves the formation of an initial "precursor" gel phase which, without the use of seeds, transforms into a mixture of both calcite and or vaterite, ${ }^{13-15}$ even in the presence of polyacrylic acids. ${ }^{16}$ The vast amount of literature on the calcium carbonate system provides extensive information on the kinetic parameters and solubility. However understanding of the precipitation mechanism is still lacking at the higher supersaturations. Early models to describe the precipitation paths consider the nucleation of different polymorphs and hydrates, which then transform into more stable modifications ${ }^{17,18}$ that can also be influenced by the presence of additive molecules. ${ }^{19,20}$ New characterization tools such as cryogenic-TEM (cryo-TEM) or X-ray microscopy demonstrate the precipitation starts with particles $\sim 30 \mathrm{~nm}$ in size, which then transform into calcite or vaterite phases, ${ }^{21-24}$

* Tel: +41216935109 Fax: +4121693 30 89. anne.aimable@epfl.ch.

${ }^{\dagger}$ Currently in EMS (Electro Medical Systems SA, CH-1260 Nyon, mdonnet@ems-ch.com). probably via agglomeration mechanisms involving amorphous calcium carbonate prenucleation clusters. ${ }^{25,26}$ This has been elegantly studied recently by cryo-TEM for the early formation of the metastable phase vaterite in the presence of stearic acid, in which orientation-dominated growth at the template interface was postulated. ${ }^{26}$ In these studies, the initial formation of vaterite and eventual transformation into calcite is difficult to control, leading to inhomogenous particles, and the substructure; size; and, in particular, size distributions are also often inhomogeneous. ${ }^{27,28}$

To produce powders for application, a better control of the powder characteristics is needed. In a previous study, ${ }^{15}$ we demonstrated the ability of a seeding method to control the precipitation evolution, even if supersaturations are high $(S>$ 30). The use of seed dispersions stabilized by poly(acrylic acid) (PAA) allowed the control of the precipitated polymorph and the specific surface area. Indirect methods led to the determination of a seed size of $8 \mathrm{~nm}$ with a number density of 2-16 seeds per $\mu \mathrm{m}^{3}$, depending on the PAA concentration. The assumption that growth took place only on the nanosized seeds was supported by comparing computed primary particle sizes and crystallite sizes from the XRD line broadening and specific surface area measurements. The seeds also affect the kinetics of the reaction, producing calcite directly rather than vaterite, which then sluggishly transforms into calcite ${ }^{24,26}$ or aragonite, depending on the reaction conditions and additives. ${ }^{16}$

The aim of the current study is to provide a more thorough investigation of the mechanism of calcite precipitation in the presence of seeds and polymeric additives which gives excellent control over particle properties; particularly to assess the early stages, to try to understand the growth mechanism by aggregation and if oriented attachment may play a role in the formation of the nanostructured calcites. Cryogenic transmission electron microscopy (Cryo-TEM) was performed to stop the reaction after a few seconds. Analysis of the evolution of the precipitation with time using a thermodynamic model predicting surface 
TABLE 1: Experimental Conditions before Mixing of the Reactants

\begin{tabular}{lll}
\hline parameter & value & comment \\
\hline$\left[\mathrm{Ca}^{2+}\right]$ & $0.022 \mathrm{M}$ & calcium in excess \\
{$\left[\mathrm{CO}_{3}^{2-}\right]$} & $0.020 \mathrm{M}$ & \\
$\mathrm{S}$ & 30 & high supersaturation of calcite \\
temp & $25{ }^{\circ} \mathrm{C}$ &
\end{tabular}

charge and interfacial tension modifications with the $\mathrm{pH}$ evolution is used, along with interparticle force calculations to propose a growth mechanism. The final stage of particle growth follows a different mechanism at the reduced supersaturation expected at the end of a batch precipitation experiment, where a ripening process is expected to dominate, which is explained in terms of the interaction of the polymeric additive present.

\section{Materials and Methods}

The reaction studied results from the mixing of calcium nitrate and potassium carbonate aqueous solutions (eq 1).

$$
\mathrm{Ca}\left(\mathrm{NO}_{3}\right)_{2}+\mathrm{K}_{2} \mathrm{CO}_{3} \stackrel{\mathrm{H}_{2} \mathrm{O}}{\longrightarrow} \mathrm{CaCO}_{3(\mathrm{~s})}+2 \mathrm{KNO}_{3}
$$

A polymeric additive is used to produce the seeds, poly(acrylic acid) (PAA 2000 Acros 18499). The preparation of reaction solutions, seed suspensions, and the batch precipitation procedure has been fully described elsewhere. ${ }^{15}$ The experimental conditions studied here can be found in Table 1, with the seed source being an in-house precipitated calcite, with a rice-grain shape, obtained with a high concentration of PAA (0.010 wt \%). The supersaturation, $S$, has been calculated using $S=\sqrt{ } \mathrm{Ps} / \mathrm{Ks}=30$ where Ps is the activity product after mixing and $\mathrm{Ks}$ is the solubility constant $(\mathrm{pKs}=8.3)$.

The particle size distribution of the resulting powders was measured by laser diffraction (Malvern Mastersizer S, $\rho=$ $2.71 \mathrm{~g} \mathrm{~cm}^{-3}$, particle refractive index $n=1.596, i=0.10$ in water). The specific surface area, $S_{\mathrm{BET}}\left(\mathrm{m}^{2} \mathrm{~g}^{-1}\right)$, was obtained by nitrogen adsorption (Brunauer-Emmett-Teller (BET) model, Gemini 2375, Micromeritics). The size of the primary particles, $d_{\mathrm{BET}}(\mu \mathrm{m})$, was also estimated by assuming spherical monodisperse particles (eq 2).

$$
d_{\mathrm{BET}}=\frac{6}{S_{\mathrm{BET}} \times \rho}
$$

Samples were observed by scanning electron microscopy (SEM, Philips XL-30 FEG). Cryogenic transmission electronic microscopy (Cryo-TEM, Philips CM-100 BioTwin) allows imaging of the precipitates at a chosen stage of evolution. To do this, a droplet of the reaction medium was deposited on a TEM support and frozen in liquid ethane $\left(-180^{\circ} \mathrm{C}\right)$. The frozen sample can be observed by TEM (observation conditions: 100 $\mathrm{kV},-182^{\circ} \mathrm{C}$ ). Selected powders were also analyzed using crosssectional transmission electron microscopy (TEM) obtained by ultramicrotomy. The dry powder was embedded in an epoxy resin matrix of Agar100, dodecenyl succinic anhydride, methyl nadic anhydride, and 2,4,6-tri (dimethylamonimethyl) phenol. The mixture of the resin and powder was placed in a drier at $60{ }^{\circ} \mathrm{C}$ for $12 \mathrm{~h}$ for the polymerization. Then the block was cut in a dry environment at room temperature with a $35^{\circ}$ Diatom diamond knife (radius of $5 \mathrm{~nm}$ ) mounted on a Reichert-Jung Ultracut E ultramicrotom. The thickness of the cross section was in the range of $80 \mathrm{~nm}$. The particle structures were studied on a Philips CM 200 TEM operating at $200 \mathrm{kV}$ at room temperature.

The crystallographic phase content was monitored using X-ray diffraction (XRD, Kristalloflex 805, Siemens, using a copper electrode with $\lambda_{\mathrm{K} 1}=1.54060 \AA$, and $\lambda_{\mathrm{K} 2}=1.54443 \AA$ ). The XRD peak broadening allows us to determine the size of the primary crystallite using the Scherrer equation. ${ }^{15}$ The solution $\mathrm{pH}$ was measured with $\mathrm{pH}$ electrodes (Orion 8115BN, Orion 720 ), and two measurements per second were recorded on a computer. TGA measurements were performed between 200 and $600{ }^{\circ} \mathrm{C}$ using a Mettler Toledo TGA/SDTA 851e under flowing air.

Results were analyzed using thermodynamic solubility calculations developed by Donnet et al. ${ }^{29}$ All equilibria were solved simultaneously considering the activity of each species in solution. This approach allows the calculation of reaction progress, crystallite size, and surface charge from experimentally measured $\mathrm{pH}$ values as a function of time. These data were compared with those obtained from a commercial thermodynamic software: StreamAnalyser from Oli Systems (http:// www.olisystems.com/). This predictive thermodynamic model is widely used in the chemical and engineering industries, in oil and gas, and in research institutes. The Oli model is based on published experimental data. A large thermodynamic databank is available, covering most of the periodic table of elements. Finally, colloidal stability calculations using freely available software (Hamaker http://ltp.epfl.ch/page65254.html ${ }^{30}$ ) were made to assess the various agglomeration processes that contribute to the growth mechanisms.

\section{Results and Discussion}

3.1. Influence of PAA Concentration. Using a seed suspension in combination with PAA allows the phase selectivity and size control of the precipitates, as described previously. ${ }^{15}$ The amount of PAA added with the seed source was $0.001,0.0033$, 0.006 , and $0.01 \mathrm{wt} \%$. The resulting powders show differences in their morphologies (Figure 1) and their specific surface area (Table 2). SEM micrographs of the precipitates show an evolution from a rhombohedral morphology $(\mathrm{PAA}=0.001 \mathrm{wt}$ $\%$, Figure 1a), to a regular rice-shape $(\mathrm{PAA}=0.01 \mathrm{wt} \%$, Figure $1 \mathrm{~d})$. This evolution is accompanied by a transition from a wellcrystallized powder to a nanostructured powder. However, these changes in the powder structure do not modify significantly the median size of the particles measured by laser diffraction (Table 2 ), indicating that the particles at high PAA concentrations are polycrystalline. X-ray powder diffraction (XRD) showed in all cases the particles were pure calcite, as expected from previous studies $^{15}$ (see the Supporting Information, S1).

The weight losses of these samples measured between 200 and $600{ }^{\circ} \mathrm{C}$ by TGA are presented in Table 3. The amount of adsorbed PAA was calculated from these quantities. The weight loss of a pure calcite (Calofort U, Specialty Minerals, $21 \mathrm{~m}^{2}$ $\mathrm{g}^{-1}$ ) was also measured under the same conditions. It presents a weight loss of $0.91 \%$, which was considered in further interpretations as a correction on the measured weight losses by simple subtraction from the weight losses observed with PAA (corrected weight loss in Table 3 ). This is quoted as a percentage of the PAA with respect to the total amount introduced for the precipitation, with respect to the powder weight. For the lowest PAA concentration $(0.001 \%)$, all the PAA is associated with the precipitated calcite. At higher PAA concentrations, there is an excess of PAA that remains in solution, up to $60 \%$ for the highest concentration $(0.01 \%)$. 

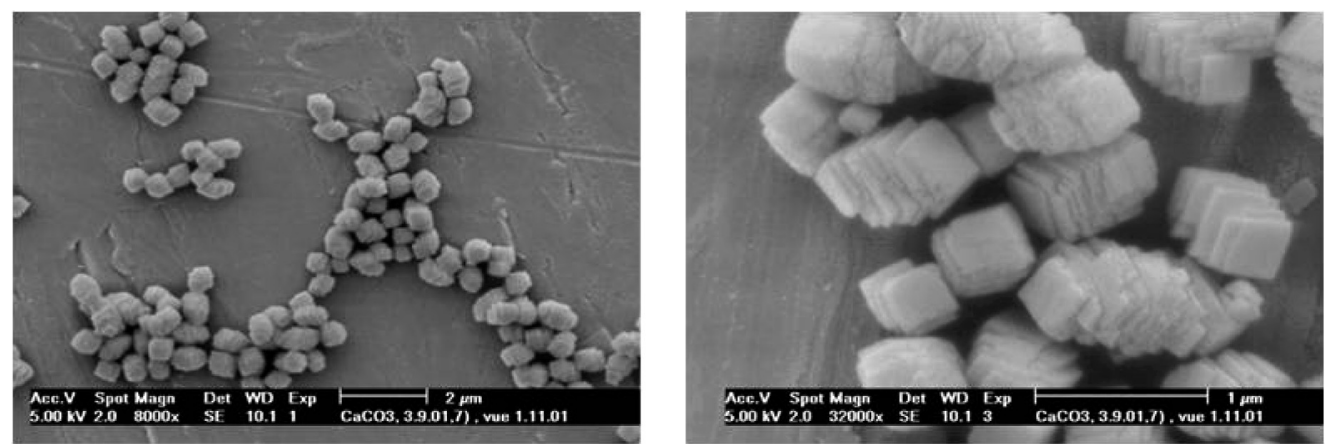

(a)
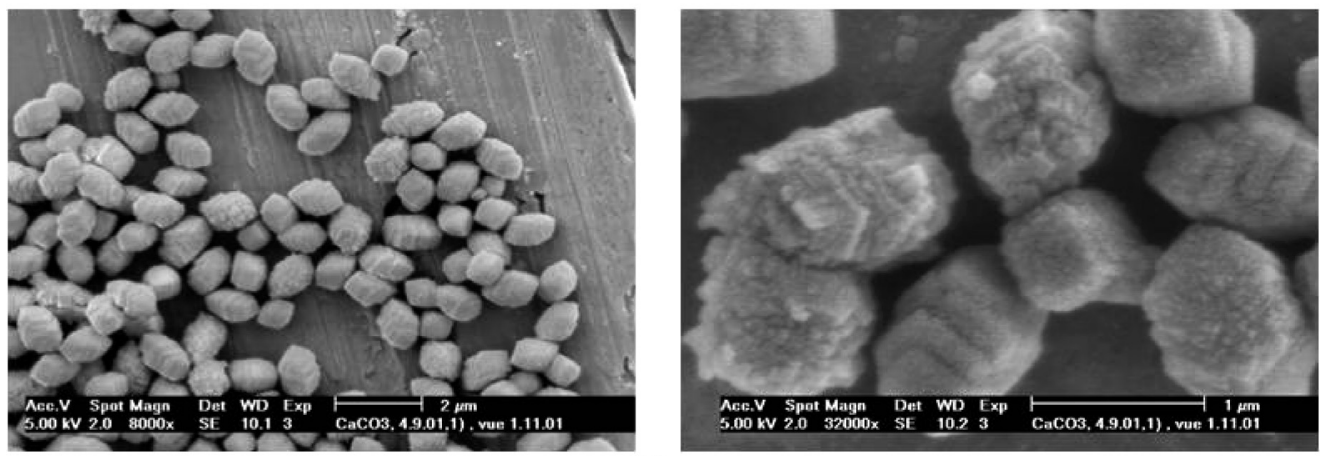

(b)
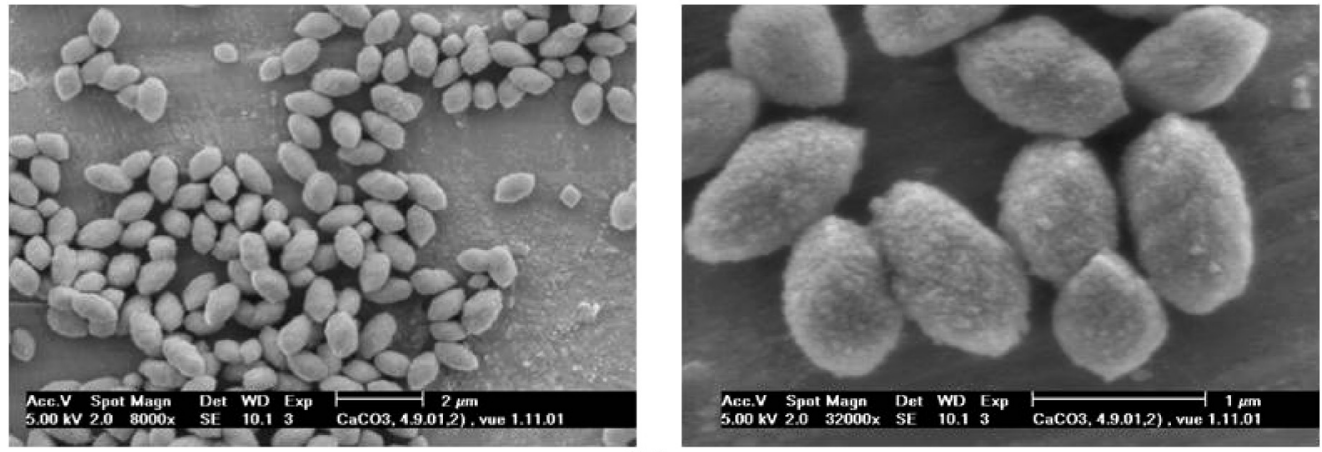

(c)
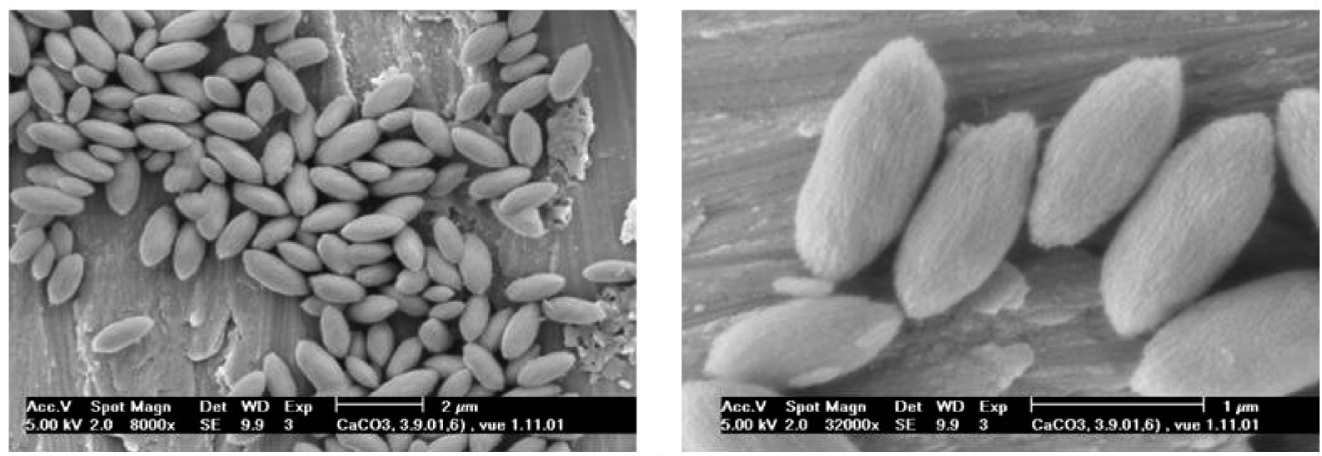

(d)

Figure 1. Calcite precipitates obtained with different PAA concentrations: PAA = (a) 0.001 , (b) 0.0033 , (c) 0.0066 , and (d) $0.01 \%$.

3.2. Cryogenic and Cross Section TEM Observations. Cryo-TEM allows the observation of the first stages of the precipitation. With the highest amount of PAA $(0.01 \mathrm{wt} \%)$, the observations made after $5 \mathrm{~s}$ of precipitation show the presence of nanoparticles between 10 and $50 \mathrm{~nm}$ (Figure 2a). After $20 \mathrm{~s}$ (Figure 2b), some bigger particles $(600 \mathrm{~nm})$ with a regular rice shape are observed. They seem to be composed of the primary nanoparticles observed after $5 \mathrm{~s}$. With the lower amount of PAA (0.001 wt \%), the observation after $13 \mathrm{~s}$ of reaction shows the presence of nanoparticles with a size less than $50 \mathrm{~nm}$ as well as bigger particles formed from these primary nanoparticles (Figure 2c). These nanoparticles are similar to those observed with the higher amount of PAA, indicating that in both conditions, the precipitation starts in the same manner. After $23 \mathrm{~s}$ at this lower PAA concentration (Figure 2d), only the large particles $(600 \mathrm{~nm})$ were observed and were more rhombohedral in form, indicating that the reaction was near completion. These times of reaction from the cryo-TEM have 
TABLE 2: Specific Surface Area and Its Corresponding Primary Particle Size, Compared with Crystallite Size from XRD Measurements and Agglomerate Size (dv50) for Different PAA Concentrations

\begin{tabular}{ccccc}
\hline $\begin{array}{c}\text { PAA concn } \\
(\%)\end{array}$ & $\begin{array}{c}S_{\mathrm{BET}} \\
\left(\mathrm{m}^{2} / \mathrm{g}\right)\end{array}$ & $\begin{array}{c}d_{\mathrm{BET}} \\
(\mathrm{nm})\end{array}$ & $\begin{array}{c}d_{\mathrm{XRD}} \\
(\mathrm{nm})\end{array}$ & $\begin{array}{c}d_{\mathrm{v} 50} \text { Malvern } \\
(\mathrm{nm})\end{array}$ \\
\hline 0.01 & 34.2 & $63 \pm 3$ & $67 \pm 6$ & 650 \\
0.0066 & 25.9 & $85 \pm 4$ & $85 \pm 7$ & 570 \\
0.0033 & 16.1 & $138 \pm 10$ & $110 \pm 20$ & 850 \\
0.001 & 6.7 & $330 \pm 40$ & $102 \pm 20$ & 500
\end{tabular}

TABLE 3: Weight Loss of the Samples Compared with Theoretical Maximum Amount of PAA in the Reaction System

\begin{tabular}{lccc}
\hline PAA concn $(\%)$ & wt loss $(\%)$ & $\begin{array}{c}\text { corrected } \\
\text { wt loss }(\%)\end{array}$ & $\begin{array}{c}\text { theor maximum } \\
\text { PAA/powder }(\%)\end{array}$ \\
\hline 0.0100 & 2.91 & 2.00 & 5.00 \\
0.0066 & 2.22 & 1.31 & 3.30 \\
0.0033 & 1.66 & 0.75 & 1.65 \\
0.0010 & 1.44 & 0.53 & 0.50 \\
0.0000 (Calofort $\mathrm{U})$ & 0.91 & & 0.00
\end{tabular}

to be interpreted with care because these are nominal times from the mixing of the reactants and the contact with the freezing liquid. When taking into account the different conditions with respect to the batch reactor, they are unlikely to be exactly the same times for both methods, but should be thought of in a more qualitative sense.

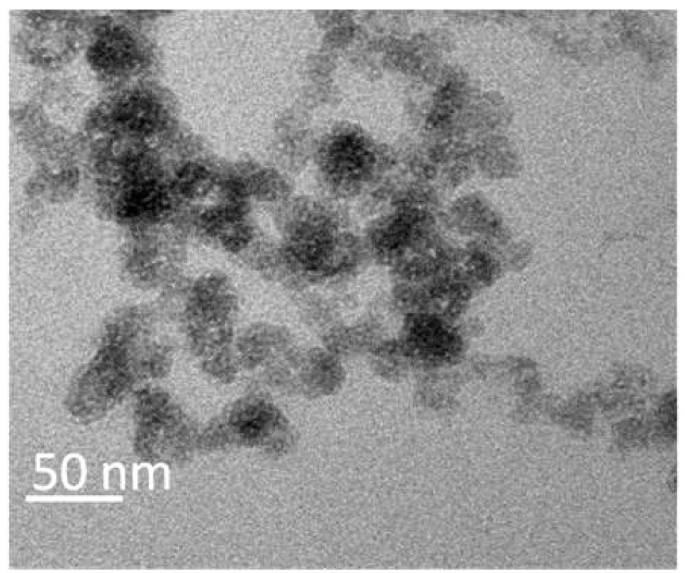

(a)

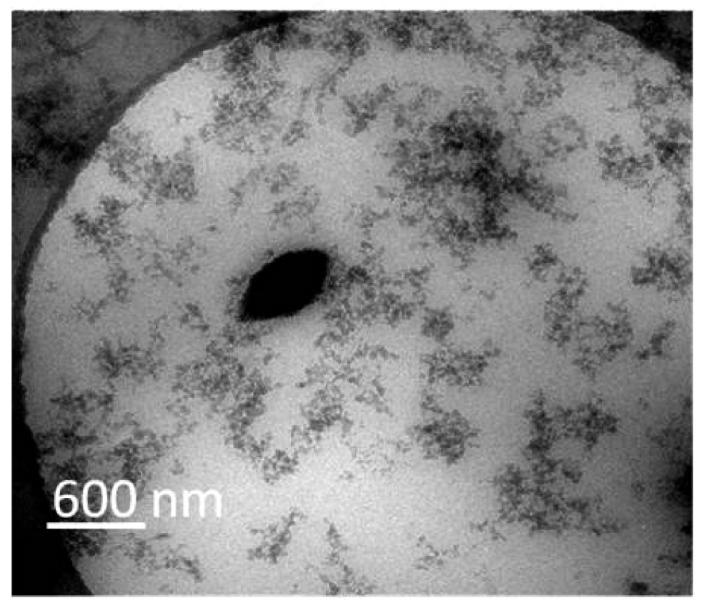

(c)
The two extremes of the types of particles, 0.001 and $0.01 \%$ PAA, were also observed in TEM cross section, and the images are shown in Figure 3. The low-PAA (0.001 wt \%) particles show a typical rhombohedral form of calcite, and electron diffraction showed them to be single crystals. The higher magnification of the center of the particle in Figure $3 b$ shows a peculiar substructure of pores within these single crystals. Imaging was carried out on several particles and at very low electron dosages to ensure that these pores were an inherent feature of the particles and not a feature of beam damage. Careful observation shows that a large number of these pores show the same rhombohedral form and crystallographic direction as the particle. This may be linked to the kinetics and oriented attachment mechanism proposed later in section 4. Electron diffraction on these particles shows sharp spots, indicating they are well crystallized (see Supporting Information S1). For the rice-shaped particles produced at the high PAA level (0.01 wt $\%$ ), quite a different substructure was observed. Many particles seemed to have a central core, which often has a rhombohedral shape (Figure 3c), that has been lost during sample preparation. The higher magnification cross section image shows a rhombohedral single crystal core surrounded by a disordered nanostructured shell (Figure 3d). Such substructures have not been revealed in previous studies when mixtures of single crystal calcite and polycrystalline vaterite are generally observed. ${ }^{24,26}$

3.3. pH Evolution. The $\mathrm{pH}$ of the reaction with $0.0100 \mathrm{wt}$ $\%$ of PAA was measured and is reported as a function of the

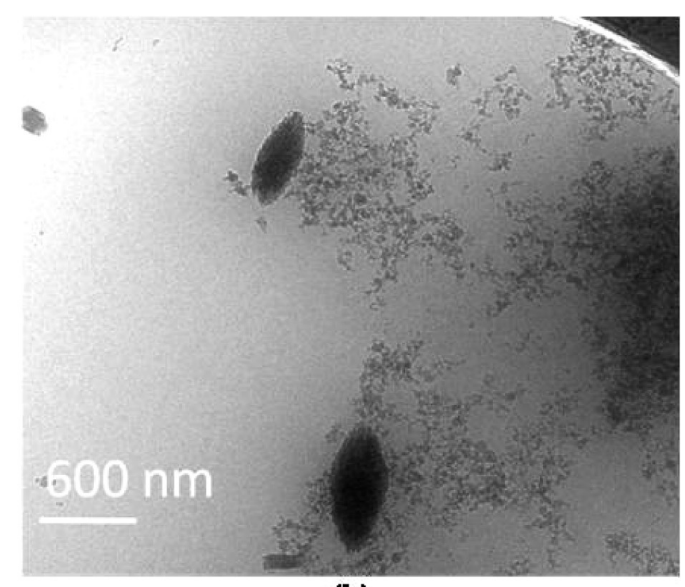

(b)



(d)

Figure 2. Cryo-TEM observations of calcite with different PAA concentrations: PAA = (1) $0.01 \%$ after $5 \mathrm{~s}$, (2) $0.01 \%$ after $20 \mathrm{~s}$, (3) $0.001 \%$ after $13 \mathrm{~s}$, and (4) $0.001 \%$ after $23 \mathrm{~s}$. 


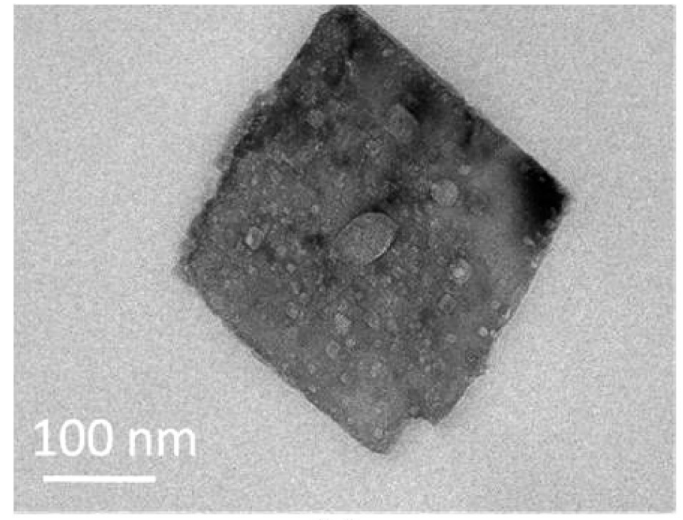

(a)



(c)

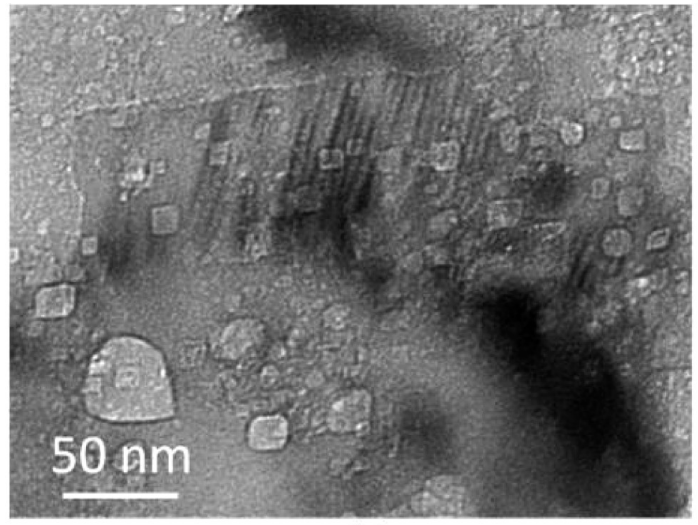

(b)

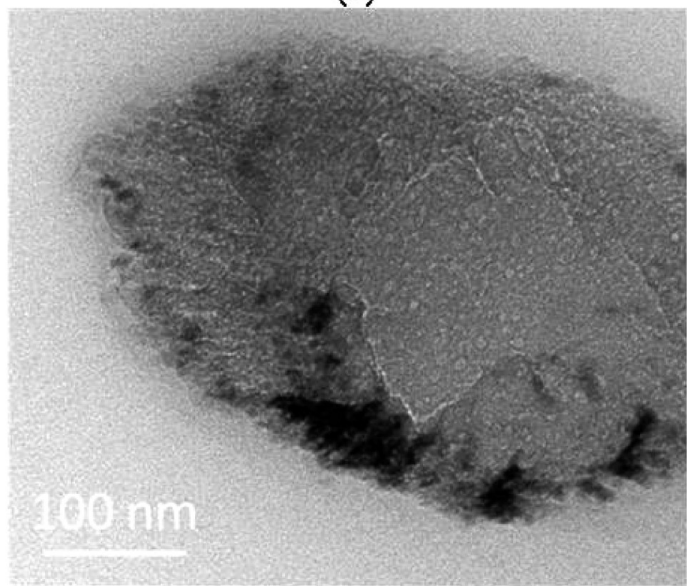

(d)

Figure 3. TEM cross section images for calcite particles produced with $(a-b)$ low $(0.001 \%)$ and $(c-d)$ high PAA $(0.01 \%)$.

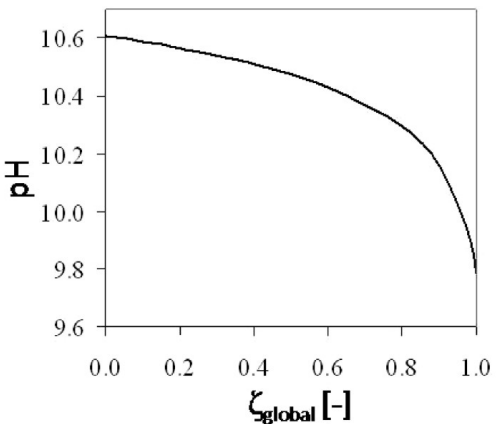

(a)

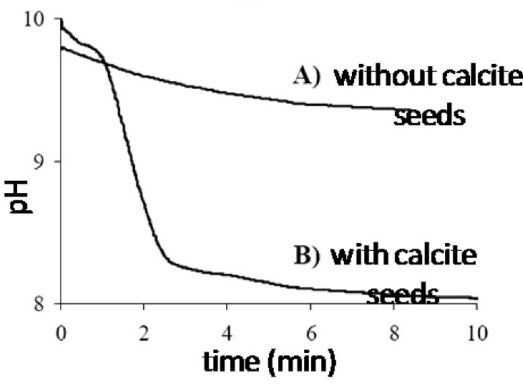

(c)

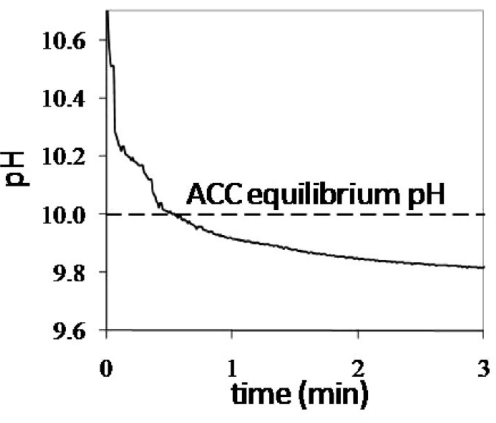

(b)



(d)

Figure 4. (a) $\mathrm{pH}$ evolution as a function of the advancement of the reaction $\xi$ with seeds and PAA concentration $0.01 \%$, (b) $\mathrm{pH}$ evolution with time and compared with $\mathrm{pH}$ equilibrium of amorphous calcium carbonate in the experimental conditions $(\mathrm{Ca} / \mathrm{C}=1.1, \mathrm{PAA}=0.01 \%),(\mathrm{c}) \mathrm{pH}$ evolution (= extent of reaction) for the precipitation reaction (A) without and (B) with the calcite seeds, and (d) repetitions of seeded precipitation reactions showing a certain degree of variability.

reaction time in Figure 4a. From the solubility calculations, it is possible to plot the $\mathrm{pH}$ as a function of the advancement of the reaction $\zeta$ (Figure $4 \mathrm{~b}$ ). The equilibrium $\mathrm{pH}$ of amorphous calcium carbonate (ACC) is also shown in Figure $4 \mathrm{~b}$ for later 


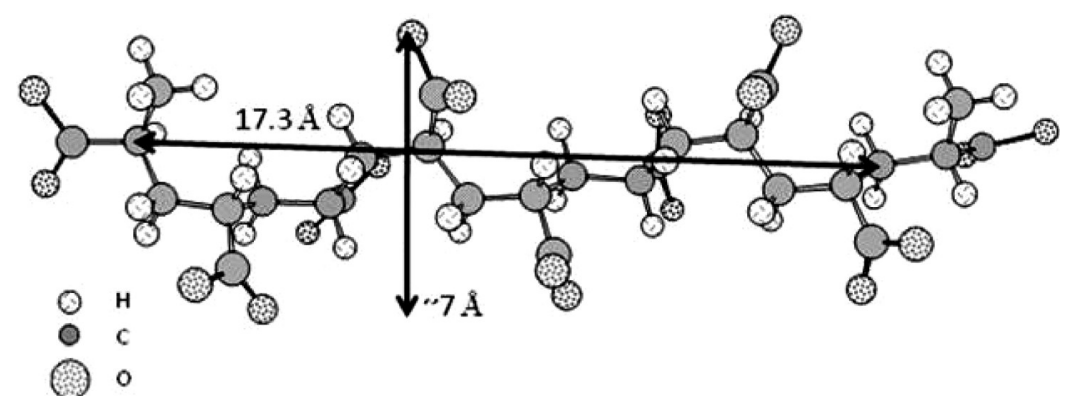

Figure 5. Fragment ( 8 units) of a dissociated PAA chain in a state of minimum energy: the distance between carboxylate groups is maximum (extended configuration).

TABLE 4: Free-Carboxylate Pairs for the Polyacrylic Acid As a Function of the Advancement of the Reaction

\begin{tabular}{cc}
\hline$\zeta$ & free carboyxlate pairs; $\mathrm{C} / \mathrm{Ca}=0.9$ \\
\hline 0.0 & $7.3 \%$ \\
0.4 & $7.5 \%$ \\
0.8 & $18.9 \%$ \\
0.9 & $29.7 \%$ \\
1.0 & $94.7 \%$
\end{tabular}

discussion. The comparison of these two graphs shows that $83 \%$ of the reaction is completed in only $5 \mathrm{~s}$, and $95 \%$ of the reaction has taken place within $30 \mathrm{~s}$. This is coherent with the cryoTEM observations presented above where primary nanoparticles (20-50 nm) were no longer observed after $23 \mathrm{~s}$ (Figure 2d). Figure $4 \mathrm{c}$ shows a clear effect of the seeding on the kinetics of precipitation (equivalent to $\mathrm{pH}$ evolution), indicating the enhanced growth rates when using seeds compared to homogeneous nucleation. Figure $4 d$ shows that even with the seeding, there is a certain variability in the second $\mathrm{pH}$ jump assumed to be associated with a transformation from the initial hydrated phase into calcite.

3.4. Surface Coverage: Adsorbed Polymer Configuration. The quantity of PAA used in the precipitation of calcite in the presence of the seeds has a strong influence on the particle morphology and microstructures, as illustrated in Figures 1 and 3. To try to gain information on the possible conformation of PAA adsorbed as a function of its concentration, two aspects were considered: (i) Where the PAA is totally dissociated and assumed to have an "extended configuration", as represented geometrically in Figure 5 using the Chem Draw software. The surface occupied by the 2000 average $M_{\mathrm{w}}$ of the PAA used can then be estimated to be $4.2 \mathrm{~nm}^{2}(0.7 \times 6 \mathrm{~nm})$ if it adsorbs in a flat "pancake" type conformation. From the TGA results, the amount of adsorbed polymer was estimated to be less than the possible weight loss, assuming all the PAA available is adsorbed on or incorporated in the precipitated calcite (Table 3, corrected weight loss/theoretical maximum). The results indicate an excess of PAA which remains in solution after the precipitation. (ii) At the $\mathrm{pH}$ of the reaction, the PAA is expected to be fully dissociated, but at the onset of the precipitation reaction, a significant number of calcium ions are in solution and may form a complex with adjacent dissociated carboxylate groups. ${ }^{31}$ This was estimated by measuring the calcium ion activity and total calcium concentration as described elsewhere. ${ }^{15}$ The percentage of carboxylate pairs not complexed by calcium as a function of degree of reaction is reported in Table 4. This shows high complexation at early stages and practically full dissociation at the end of the reaction. Such complexation may affect the degree and kinetics of PAA adsorption as well as its conformation.

\section{Mechanism for Seeded Calcite Precipitation at High Concentration}

We believe there are four stages to the growth mechanism of the seeded calcite precipitation, as shown schematically in Figure 6. The first stage is the formation of an amorphous hydrous calcite gel, as seen by other investigators. ${ }^{21,26}$ This hydrous amorphous calcium carbonate is then consumed and transformed into calcite by a rapid growth on the existing calcite seeds, forming the $10-50 \mathrm{~nm}$ particles seen in the cryo-TEM. In a third stage, these particles agglomerate to form particles of around $600 \mathrm{~nm}$, as observed by laser diffraction and cryoTEM. These nanostructured secondary particles remain well dispersed, but in a fourth stage of the mechanism, they undergo a ripening to reduce the interfacial area, both internally and externally, and hence, the free energy of the system. The amount of PAA in the precipitating system has its most pronounced effect on the final ripening stage, forming either the rhombohedral or rice grain particles as well as influencing the internal structure of these particles. We will now discuss each of the four stages with either experimental results or theoretical calculations (or both) to support our proposed growth mechanism.

4.1. First Stage: Formation of a Hydrated Amorphous Gel. At the beginning of the reaction, a continuous gel phase is observed in the reactor, and then after about $20 \mathrm{~s}$, a welldispersed white precipitate appears. This very rapid transformation into a well-dispersed phase coincides with the second "jump" in $\mathrm{pH}$ (Figures 4b and d). The large number of nanoparticles formed as shown by cryo-TEM in Figure 2 supports the appearance of such a pseudogel. The $\mathrm{pH}$ evolution is composed of two $\mathrm{pH}$ jumps. The first drop in $\mathrm{pH}$, up to about $5 \mathrm{~s}$, is explained by the formation of a metastable hydrate phase, as previously observed by many researchers. ${ }^{21,24-26}$ This metastable phase is formed to relieve the high supersaturation produced during the rapid mixing of the reactants. The $\mathrm{pH}$ at which this phase roughly stabilizes for a short period $(\mathrm{pH}=$ $10.2-10.0$ for $5-20 \mathrm{~s}$ ) is close to that of an amorphous calcium carbonate as identified by Cölfen et al. (ACCI, pKs $=7.51) .{ }^{25}$ The precipitation of such an amorphous calcium carbonate phase is faster, as it can lower the free energy of the system into a local minimum because the ionic species can remain in their hydrated state. The precipitation of this hydrated phase could take place either on the calcite seeds or independently.

The cryo-TEM images in Figure 2a show very small particles $<10 \mathrm{~nm}$ with lower contrast than the $20-30 \mathrm{~nm}$ particles, which seem to have an amorphous or poorly ordered substructure. Unfortunately, the samples were too beam-sensitive to use electron diffraction to try to distinguish between crystalline and poorly ordered particles. When the equilibrium $\mathrm{pH}$ of the hydrated ACC phase is approached, the transformation into the anhydrous phase occurs. This phenomenon is accompanied by a second jump of $\mathrm{pH}$ in Figure $4 \mathrm{~b}$, at $\sim 17$ s. This exactly 


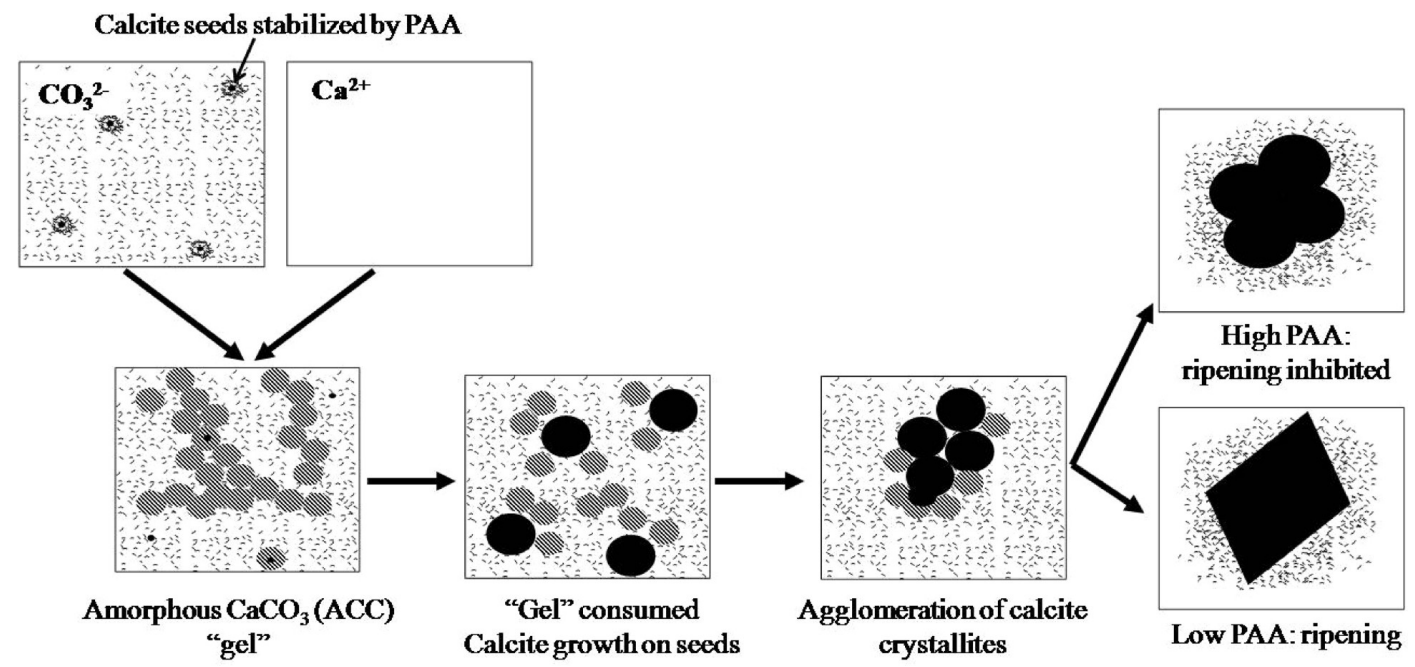

Figure 6. Schematic summary of the seeded calcite precipitation mechanism.

corresponds to the visual observation of the transformation from the gel phase to a sol in the batch reactor and is the beginning of the second stage of the growth mechanism (see Supporting Information S1). Although the presence of an amorphous phase ACC as the hydrated phase, coherent with the thermodynamic calculations, could not be confirmed in the TEM, we will refer to the hydrated phase as ACC for the rest of the manuscript.

4.2. Second Stage: Calcite Growth on Seeds. The transformation into the thermodynamically stable phase, calcite, is also relatively quick, with most of the transformation occurring within $30 \mathrm{~s}$ of the start of the precipitation. This rapid transformation into calcite is thought to be mainly governed by the presence of the calcite seeds (Figure 4c), presumably by reducing the activation energy for the transformation by consuming the hydrated phase, which can be sluggish without a calcite template. ${ }^{24,26}$

The first stage of the reaction is not influenced by the PAA concentration according to cryo-TEM analysis which demonstrated similar precipitates, whatever the PAA concentration (Figure 2), but because the initial number of seeds is determined by the PAA concentration, ${ }^{15}$ it will influence the final crystallite size, assuming the same quantity of the hydrated phase is precipitated in all cases (i.e., the presence of the seeds do not influence greatly the hydrate precipitation). With a higher amount of PAA giving a higher number of calcite seeds, the final crystallite size should be smaller if growth of the calcite is uniquely on the seeds. This evolution can be calculated from our thermodynamic model ${ }^{29}$ and advancement of reaction (from the $\mathrm{pH}$ evolution) and is shown in Figure 7 . We report the simulated size of calcite by considering the number of calcite seeds of $11 \times 10^{15} \mathrm{dm}^{-3}$ with 0.0100 wt $\%$ of PAA, and $4 \times$ $10^{15} \mathrm{dm}^{-3}$ with 0.0010 wt $\%$ of PAA.

The calculated final crystallite sizes are coherent with the crystallite sizes measured by XRD and reported in Table 2. At this stage, the majority of the calcium in solution has been precipitated, and the next stage of the proposed mechanism is the agglomeration of the nanosized primary particles (40-70 $\mathrm{nm}$ ) to produce the final secondary particles, as seen by laser diffraction and SEM (Figure 1). The evolution of the dominant species in solution was also calculated as a function of the $\mathrm{pH}$ and is shown in Figure 8. We see that these are the hydrogen carbonate, carbonate, and calcium ions, in equilibrium with precipitated calcite. The relative change in concentration of these species as the reaction advances is very small.

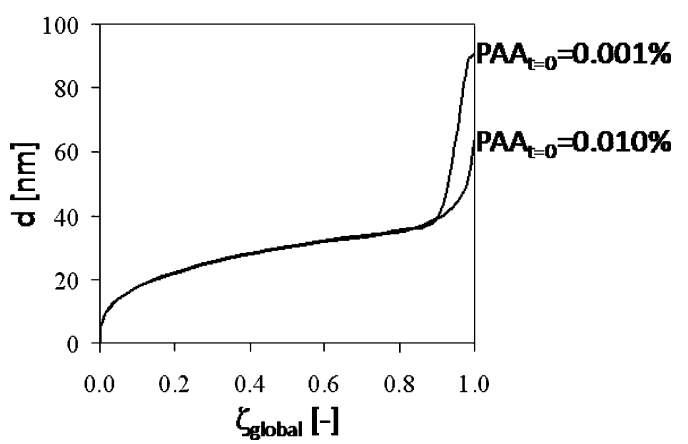

Figure 7. Simulation of the primary particle size with the advancement of the reaction $\xi$; at the beginning, $5 \times 10^{16}$ nanoparticles of the amorphous phase precipitate independently of the PAA concentration. When $\zeta=0.9$, the particle size depends on the number of initial seeds, which is with $\mathrm{PAA}_{t=0}=0.01 \% 11 \times 10^{15}$ particles $\mathrm{dm}^{-3}$; with $\mathrm{PAA}_{t=0}$ $=0.001 \% 4 \times 10^{15}$ particles $\mathrm{dm}^{-3}$.

4.3. Third Stage: Agglomeration of Primary Particles and Stabilization of the Agglomerates. Role of the PAA. The agglomeration of nanoparticles starting between 5 and $13 \mathrm{~s}$ as observed by cryo-TEM probably has two energetic aspects: (i) attractive van der Waals forces, which dominate a low electrostatic repulsion between the particles, and (ii) a decrease in the global energy of the considered system by the creation of crystal-crystal interfaces (oriented attachment). The surface potential of the particles, $\Phi_{0}$, and the interfacial energy between the crystal and the solution, $\gamma$, were calculated from the thermodynamic solubility model (Figure 7), described in more detail elsewhere. ${ }^{29}$

At the beginning of the reaction, the surface potential, $\Phi_{0}$, is close to the isoelectric point, and the formation of a hydrate phase gives a low interfacial energy, $\gamma$. This leads to a chaotic agglomeration of the first precipitated nanoparticles and, thus, to the formation of an open network: our so-called pseudogel. A drastic increase in the interfacial tension is observed when the transformation of ACC to calcite starts $(\zeta=0.92)$, whereas the surface potential evolution is low. This increase in the interfacial tension gives a high driving force for oriented attachment to minimize their surface interaction with the solution, whereas the low surface charge is insufficient to avoid the agglomeration of the primary nanoparticles. ${ }^{15,16}$ Interparticle potential calculations for these 40 to $90 \mathrm{~nm}$ primary particles (from $\zeta=0.92$ to 1.00 ) were performed using the Hamaker program (Hamaker http://ltp.epfl.ch/page65254.html ${ }^{30}$ ). 


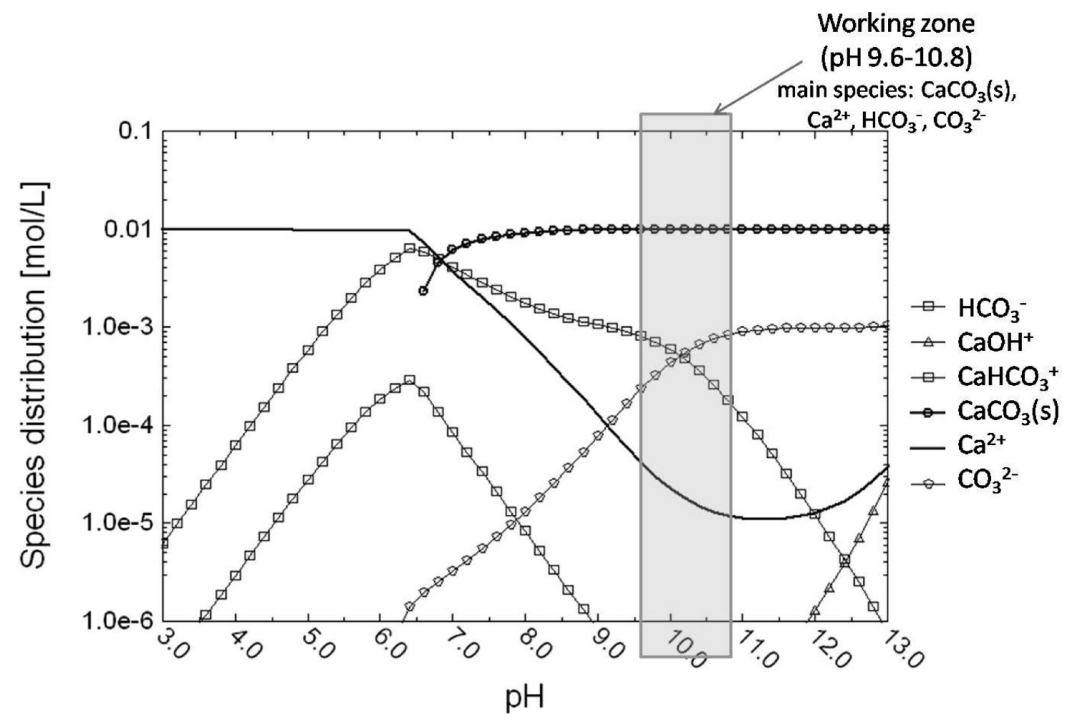

Figure 8. Evolution of the dominant species in solution in equilibrium with calcite precipitation.

TABLE 5: Parameters Used to Make Interparticle Potential Calculations Using the Hamaker Program (Hamaker http:// Itp.epfl.ch/page65254.html ${ }^{30}$ )

\begin{tabular}{ccccc}
\hline $\begin{array}{c}\text { particle } \\
\text { diameter }(\mathrm{nm})\end{array}$ & $\begin{array}{c}\zeta \text { potential } \\
(\mathrm{mV})\end{array}$ & $\begin{array}{c}\text { adsorbed layer } \\
\text { thickness of PAA }\end{array}$ & ionic concn & $\begin{array}{c}\text { potential well } \\
(-) / \text { barrier }(+)(\mathrm{kT})\end{array}$ \\
\hline 40 & -7 & none & 0.004 & -10 attractive \\
model
\end{tabular}

${ }^{a}$ A fully extended PAA of molecular weight of 2000 would have a length of $6 \mathrm{~nm}$ (see section 3.4); the values of 1 and 5 chosen are discussed elsewhere. ${ }^{38}$

The calculations made using the data shown in Table 5 indicate that the particles are not stable without an adsorbed layer of PAA. During the rapid transformation of the hydrated ACC into the calcite, we do not expect the PAA still in solution to be able to adsorb quickly enough on these newly formed surfaces, and it does so only once the rapid aggregation taking place in this first $30 \mathrm{~s}$ of the reaction has more or less been completed. The depth of the attractive interparticle potential well was estimated at an interparticle distance of $0.5 \mathrm{~nm}$, where the final strongly adsorbed water layers are expected to avoid immediate particle-particle contact and will lubricate particle movement, allowing an oriented attachment to occur after transformation into calcite. ${ }^{32,33}$ The $500 \mathrm{~nm}$ rice shape particles observed in TEM and measured by laser diffraction and photon correlation spectroscopy after 1 min reaction ${ }^{34}$ indicate that these particles are stabilized against agglomeration by an adsorbed PAA layer. This regime of aggregation and PAA adsorption may overlap, and the outer layer of the aggregates $(500 \mathrm{~nm})$ may have significant quantities of adsorbed polymer, which may explain the different ripening phenomena discussed in the next section.

4.4. Fourth Stage: Ripening and Ripening Inhibition As a Function of PAA Concentration. PAA plays an important role in the final morphology and size, as shown in Figure 3; low PAA $(0.001 \%)$ shows single crystal rhombs (Figure $3 a$ and Supporting Information $\mathrm{S} 1$ ), and high PAA shows rice grain shape particles with a single crystal core and a polycrystalline shell (Figure 3c). Its influence will depend on how it can adsorb onto the surface of the precipitating calcite. We saw in section 3.4 that a significant amount of the PAA is expected to be complexed by the free calcium ions at the beginning of the
TABLE 6: Diffusion Coefficients of the Different Species of the System

\begin{tabular}{lc}
\hline species & $D\left(\mathrm{~m}^{2} / \mathrm{s}\right)$ \\
\hline $\mathrm{CO}_{3}^{2-}$ & $5.5 \times 10^{-10}$ \\
$\mathrm{Ca}^{2+}$ & $4.1 \times 10^{-10}$ \\
PAA & $3.0 \times 10^{-10}$
\end{tabular}

reaction, but since the surface potential of the precipitated calcite at low $\zeta$ is also low, PAA may adsorb. Because the diffusion coefficient of PAA is lower than those of $\mathrm{Ca}^{2+}$ and $\mathrm{CO}_{3}{ }^{2-}$ (Table 6 ), the amount of PAA adsorbed is probably small. The significant difference in final morphology of the high $(0.01 \%)$ and low $(0.001 \%)$ PAA is thus more related to the final stages of the reaction: for low PAA, there is little excess, whereas for high PAA, there is a significant excess in solution (Table 3).

The adsorption of PAA has been recently shown by molecular dynamics simulations ${ }^{21}$ to be slower with lower adsorption energy than polyaspartic acid of similar molecular weight and dissociated carboxylate groups. This was attributed to the different complexation behavior of the polymers and a favorable interaction of the nitrogen-containing backbone of the polyaspartic acid. During the rapid agglomeration of the initial stages of reaction, with low PAA adsorption, the nanocrystals may orient to lower the higher interfacial energy as the transformation into calcite takes place, allowing a single crystal-like particle at low PAA. During the rapid agglomeration, interstitial fluid may be trapped, still containing both PAA and calcium: the pores formed (Figure 3c) are sometimes rhombohedral in shape suggesting an internal ripening. This could also be a consequence of oriented attachment that does not lead to densely packed particles because of the rapid agglomeration kinetics 


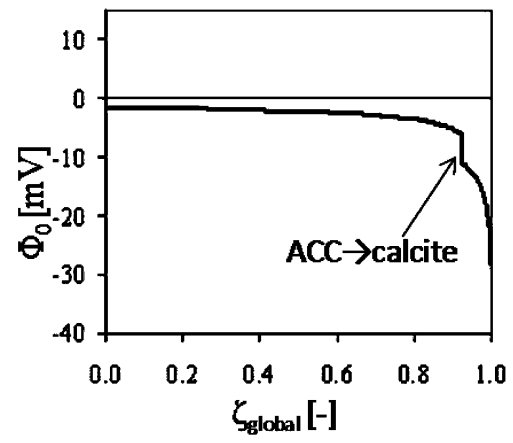

(a)

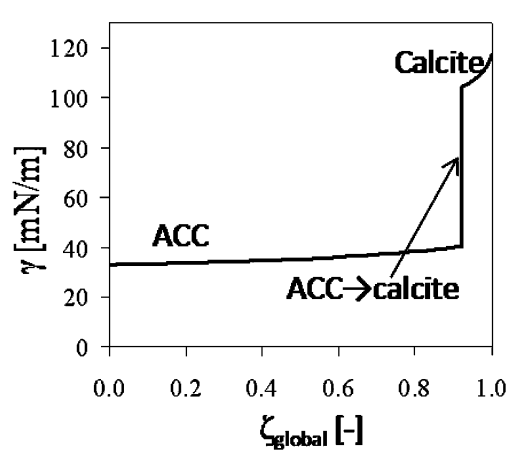

(b)

Figure 9. Evolution10 of (a) the surface potential $\left(\Phi_{0}\right)$ and (b) the interfacial energy $(\gamma)$ with the advancement of the reaction for PAA $t=0=$ $0.01 \%$.

and has been previously postulated for oriented attachment selfassembly mechanisms. ${ }^{35-37}$ The low excess of PAA does not stop ripening or disrupt the external faces of the particles that take on a well formed rhombohedral calcite shape.

For the high PAA concentration, the rapid agglomeration at early stages seemed, from the Cryo-TEM, to be the same as for the low PAA, and the core of the rice shape particle formed are, in fact, is very similar in form and well crystallized. The outer shell is nanocyrstalline and shows no alignment between the crystals (TEM dark, solid images; see Supporting Information S1). Since there is an excess of PAA, the surface of these crystals can be assumed to be fully covered with PAA, perhaps in a mixed configuration of pancake and brush, because of the significant excess of PAA. ${ }^{38}$ With this excess of PAA, the residence time at the growth steps is expected to be long enough, as indicated by molecular dynamic simulations, ${ }^{39}$ to inhibit further ripening, which can take place for either smaller molecules or at the lower PAA concentrations.

\section{Conclusion}

Calcium carbonate precipitation in a $20 \mathrm{~mL}$ fed-batch reactor showed good control of the precipitation could be achieved when using a seeding suspension stabilized by PAA. The observation of the first stages of the precipitation by Cryo-TEM revealed that the reaction started with the germination of nanoparticles $<10 \mathrm{~nm}$, which then grew on the calcite seeds rapidly $(<20 \mathrm{~s})$. These $50 \mathrm{~nm}$ particles then grew via a mechanism dominated by agglomeration for both low and high PAA concentrations. Further thin section TEM analysis of the final particles showed different substructures, depending on the PAA concentration in the starting solutions.

At low PAA solution contents $(0.001 \%)$, the particles show a well crystallized rhombohedral form. These particles have internal pores that are also often rhombohedral in shape, which are interpreted as being a consequence of an oriented attachment driven by the change in interfacial energy as the initial hydrous amorphous calcium carbonate precipitation product transforms to calcite on the seeds present. The findings were supported by thermodynamic calculations of interfacial energy and $\mathrm{pH}$ changes as a function of the degree of reaction. At higher starting concentrations of PAA, the final particles have much higher specific surface areas and a rough nanocyrstalline shell around a well crystallized core.

Cryo-TEM studies suggest that the initial mechanisms were very similar for low and high PAA contents, supported by the similarity between the crystalline cores (high PAA) and the final particle at low PAA. Thermogravimetric data show an excess of PAA remains in solution, and the rough rice shaped particles should have surfaces saturated with PAA, preventing further ripening toward the type of classic calcite rhombohedral crystals seen for the low PAA precipitation conditions.

Acknowledgment. The authors thank D. Laub, C. Soare, P. Buffat (TEM, Cryo-TEM), and C. Morais for nitrogen adsorption measurements. This work was financially supported by the Swiss OFES (Office Fédéral de l'Education et de la Science), Contract no. OFES: 99.0449-1, in the frame of a European project in the fifth Framework, program GROWTH project SFTR no. G5RDCT99-0123.

Supporting Information Available: Figure 1: X-ray powder diffraction pattern of calcite rice shaped particles produced at high PAA concentration (0.01 wt \%), corresponding to pure calcite (JCPDS 05-0586). Figure 2: Transmission electron microscopy and electron diffraction of calcite particles produced at low and high PAA concentrations in dark field image mode. Figure 3: Picture showing the transition from a gel to a precipitate in the first seconds of calcite precipitation. This material is available free of charge via the Internet at http:// pubs.acs.org.

\section{References and Notes}

(1) Teir, S.; Eloneva, S.; Zevenhoven, R. Energy Convers. Manage. 2005, 46, 2954-2979.

(2) Shan, D.; Wang, Y.; Xue, H.; Cosnier, S. Sens. Actuators, B 2009, 136, 510-515.

(3) Espinola, F.; Moya, M.; Fernandez, D.; Castro, E. J. Food Eng. 2009, 92, 112-118. 121.

(5) Zhao, D.; Zhu, Y.; Li, F.; Ruan, Q.; Zang, S.; Zhang, L.; Xu, F. Mater. Res. Bull. 2010, 45, 80-87.

(6) Yang, H.; Yao, W.; Yang, L.; Ma, X.; Wang, H.; Ye, F.; Wong, K. J. Cryst. Growth 2009, 311, 2682-2688.

(7) Tang, H.; Yu, J.; Zhao, X. Mater. Res. Bull. 2009, 44, 831-835.

(8) Su, Y.; Yang, H.; Shi, W.; Guo, H.; Zhao, Y.; Wang, D. Colloids Surf., A 2010, 355, 158-162.

(9) Mann, S. Nature 1993, 365, 499-505.

(10) Mann, S.; Ozin, G. A. Nature 1996, 382, 313-318.

(11) Mann, S.; Didymus, J. M.; Sanderson, N. P.; Heywood, B. R.; Samper, E. J. A. Faraday Trans. 1990, 86, 1873.

(12) Finnemore, A. S.; Scherer, M. R. J.; Langford, R.; Mahajan, S.; Ludwigs, S.; Meldrum, F. C.; Steiner, U. Adv. Mater. 2009, 21, 39283932.

(13) Franke, J.; Mersmann, A. Chem. Eng. Sci. 1995, 50, 1737-1753.

(14) Kamiya, K.; Sakka, S.; Terada, K. Mater. Res. Bull. 1977, 12, 10951102

(15) Donnet, M.; Bowen, P.; Jongen, N.; Lemaitre, J.; Hofmann, H. Langmuir 2005, 21, 100-108. 
(16) He, L.; Xue, R.; Song, R. J. Solid State Chem. 2009, 182, 10821087.

(17) Chakraborty, D.; Bhatia, S. K. Ind. Eng. Chem. Res. 1996, 35, 19851994.

(18) Chakraborty, D.; Bhatia, S. K. Ind. Eng. Chem. Res. 1996, 35, 19952006

(19) Nan, Z.; Chen, X.; Yang, Q.; Chen, Z. Mater. Res. Bull. 2010, 45, $722-726$.

(20) Wang, X.; Sun, H.; Xia, Y.; Chen, C.; Xu, H.; Shan, H.; Lu, J. R. J. Colloid Interface Sci. 2009, 332, 96-103.

(21) Cölfen, H.; Qi, L. Chemistry 2001, 7, 106-116.

(22) Rieger, J.; Thieme, J.; Schmidt, C. Langmuir 2000, 16, 8300-8305.

(23) Rieger, J.; Haedicke, E.; Rau, I. U.; Boeckh, D. Tenside, Surfactants, Deterg. , 34, 430-435.

(24) Liu, J.; Rieger, J.; Huber, K. Langmuir 2008, 24, 8262-8271.

(25) Gebauer, D.; Volkel, A.; Colfen, H. Science 2008, 322, 1819-1822.

(26) Pouget, E. M.; Bomans, P. H. H.; Goos, J. A. C. M.; Frederik, P. M.; de With, G.; Sommerdijk, N. A. J. M. Science 2009, 323, 1455 1458.

(27) Li, S.; Yu, L.; Geng, F.; Shi, L.; Zheng, L.; Yuan, S. J. Cryst. Growth 2010, 312, 1766-1773.

(28) Wan, P.; Zhao, Y.; Tong, H.; Yang, Z.; Zhu, Z.; Shen, X.; Hu, J. Mater. Sci. Eng., C 2009, 29, 222-227.
(29) Donnet, M.; Bowen, P.; Lemaître, J. J. Colloid Interface Sci. 2009, 340, 218-224.

(30) Aschauer, U.; Burgos-Montes, O.; Moreno, R.; Bowen, P. J. Dispersion Sci. Technol., in press.

(31) Iida, S. Biophys. Chem. 1996, 57, 133-142.

(32) Klein, J.; Raviv, U.; Perkin, S.; Kampf, N.; Chai, L.; Giasson, S. J. Phys. Condens. Matter 2004, 16, S5437-S5448.

(33) Spagnoli, D.; Banfield, J. F.; Parker, S. C. J. Phys. Chem. C 2008, 112, 14731-14736.

(34) Bowen, P.; Donnet, M.; Bidiville, A.; Pujol, O.; Soare, L. C.; Lemaître, J. 16th Symp. Ind. Cryst. 2005, 1.

(35) Wang, T.; Colfen, H.; Antonietti, M. J. Am. Chem. Soc. 2005, 127, $3246-3247$.

(36) Schwahn, D.; Ma, Y.; Colfen, H. J. Phys. Chem. C 2007, 111, 3224-3227.

(37) Colfen, H.; Antonietti, M. Mesocrystals and Nonclassical Crystallization; John Wiley \& Sons, Ltd: Chichester, UK, 2008.

(38) Bowen, P.; Carry, C.; Luxembourg, D.; Hofmann, H. Powder Technol. 2005, 157, 100-107.

(39) Aschauer, U. Ph.D. Thesis, Ecole Polytechnique Fédérale de Lausanne, no. 4166, 2008.

JP103787P 